\title{
Helicobacter pylori CagA induces tumor suppressor gene hypermethylation by upregulating DNMT1 via AKT-NFkB pathway in gastric cancer development
}

\author{
Bao-gui Zhang ${ }^{1,2, *}$, Lei Hu ${ }^{1, *}$, Ming-de Zang ${ }^{1, *}$, He-xiao Wang ${ }^{1}$, Wei Zhao ${ }^{3}$, Jian- \\ fang $\mathrm{Li}^{1}$, Li-ping Su${ }^{1}$, Zhifeng Shao ${ }^{4}$, Xiaodong Zhao ${ }^{4}$, Zheng-gang Zhu ${ }^{1}$, Min Yan ${ }^{1}$, \\ Bingya Liu ${ }^{1}$ \\ ${ }^{1}$ Shanghai Key Laboratory of Gastric Neoplasms, Department of Surgery, Shanghai Institute of Digestive Surgery, Ruijin \\ Hospital, Shanghai Jiao Tong University School of Medicine, Shanghai, People's Republic of China \\ ${ }^{2}$ Affiliated Hospital of Jining Medical University, Jining, People's Republic of China \\ ${ }^{3}$ Department of Microbiology, Shanghai Jiao Tong University School of Medicine, Shanghai, People's Republic of China \\ ${ }^{4}$ Bio-ID Center, School of Biomedical Engineering, Shanghai Jiao Tong University, Shanghai, People's Republic of China \\ *These authors have contributed equally to this work
}

Correspondence to: Bingya Liu, e-mail: liubingya@sjtu.edu.cn

Keywords: gastric cancer development, H. pylori CagA, DNMT1, hypermethylation, AKT-NF-kB pathway

Received: August 24, 2015

Accepted: January 17, 2016

Published: February 02, 2016

\section{ABSTRACT}

Methylation of CpG islands in tumor suppressor gene prompter is one of the most characteristic abnormalities in Helicobacter pylori (HP)-associated gastric carcinoma (GC). Here, we investigated the pathogenic and molecular mechanisms underlying hypermethylation of tumor suppressor genes in HP induced GC development. We found that tumor suppressor genes hypermethylation, represented by MGMT, positively correlated with CagA in clinical specimens, gastric tissues from HP infected C57 mice and GC cell lines transfected by CagA or treated by HP infection. CagA enhanced PDK1 and AKT interaction and increased AKT phosphorylation. The P-AKT subsequent activated NFKB, which then bound to DNMT1 promoter and increased its expression. Finally, the upregulated DNMT1 promoted tumor suppressor genes hypermethylation with MGMT as a representative. In conclusion, CagA increased tumor suppressor genes hypermethylation via stimulating DNMT1 expression through the AKT-NFKB pathway.

\section{INTRODUCTION}

A causal relationship between $\mathrm{HP}$ and $\mathrm{GC}$ was first postulated by Marshall and Warren in 1983 [1]. Recent studies indicate that both intestinal and diffuse types of GC are strongly associated with HP infection [2]. Most (89\%) HP contain a contiguous cag pathologinicity island (cag-PAI), which encodes a known virulence factor CagA [3]. It has been reported that CagA plays an important role in GC carcinogenesis as an oncoprotein [3]. Besides, the internal organization of the cag-PAI appears to be highly conserved $[4,5]$. It is known that HP has contact-dependent mechanisms to interact with and modify epithelial cells, including a type IV secretion system (TFSS) that injects CagA into host cells [6]. CagA has multiple effects on epithelial cells, including apical junction modification and cell polarity perturbation [7]. Although the exact mechanism of HP-associated GC is still elusive, long-standing bacterial infection and prolonged chronic inflammation are thought to generate a carcinogenic environment that gradually causes epigenetic reprogramming of host cells in the stomach [2].

Alteration of epigenetic information is involved in the development of many cancers and other diseases $[8,9]$. DNA methylation is contributing mechanism of epigenetic transmission. Aberrant hypermethylation of promoter region $\mathrm{CpG}$ islands of tumor suppressor gene is involved to a greater extent in carcinogenesis in the stomach than in other human tissues or organs [10]. Kang and his group investigated the methylation profile in multistep lesions of the stomach and determined the methylation frequency 
of 12 genes, including O6-methylguanine-genes DNA methyltransferase (MGMT). They demonstrated that hypermethylation of certain tumor suppressor occurred in GC carcinogenesis and accumulated during progression of the gastric lesion along the multistep carcinogenesis pathway [11]. The gene MGMT has a CpG island within its promoter and thus its expression is significantly regulated by DNA methylation [12]. Chan et al. first demonstrated HP-associated hypermethylation in gastric epithelia, which was further verified in a recent study $[13,14]$. Ushijima et al. compared methylation levels of eight regions in HP positive and HP negative individuals, and found that methylation levels of several $\mathrm{CpG}$ islands in HP-positive individuals were 5.4 to 303 -fold higher than the corresponding levels in the HP-negative GC individuals [15]. Interestingly, previous studies have noted that methylated $M G M T$ was significantly associated with $\mathrm{CagA}^{+} \mathrm{HP}$ infection $(p<0.035)$ [14]. Development of DNA methylation biomarkers (MGMT) for the purposes of cancer screening, cancer risk assessment, and chemotherapy sensitivity prediction is currently evaluated in clinical trials [14]. However, despite this clear correlation between DNA methylation and HP infection, the mechanism by which HP causes hypermethylation of tumor superessor genes is unknown.

DNA methylation was mainly regulated by DNA methyltansferase family (DNMTs) [10], so we presumed that HP regulated suppressor gene promoter hypermethylation through DNMTs. A potential candidate methyltansferase is DNMT1, which has been widely implicated in the malignant transformation of various cancers [16]. In particular, DNMT1 is frequently overexpressed in cancers and contributes significantly to cancer-associated epigenetic silencing of tumor suppressor genes [17].

In this study, we found that CagA down regulated the MGMT expression by inducing hypermethylation in its promoter region, suggesting that CagA might induce gastric carcinogenesis by causing hypermethylation of tumor suppressor genes, with the MGMT as a representative.

\section{RESULTS}

\section{$M G M T$ was hypermethylated and its expression was downregulated in CagA+ tissues}

To investigate epigenetic mechanisms of HP induced GC, promoter methylation of tumor suppressor genes, represented by MGMT, was detected by MSP in GC tissues. We grouped surgically resected GC tissues into HP+ and HP- according to the standard rapid urease test (RUT) (Figure 1A). HP+ tissues were then subjected to RT-PCR to amplify CagA, and those tissues in which CagA could be amplified were classified as $\mathrm{CagA}^{+}$(Figure 1B). Methylation specific PCR (MSP) analysis of GC related tumor suppressor genes was performed on DNA samples extracted from frozen tissues (Figure 1C). MGMT was selected to be the representative gene. We found that the average methylation degree of the MGMT gene in $\mathrm{CagA}^{+}$samples was significantly higher than that in CagA' samples $(p<0.05)$ (Figure 1C). Similarly, the ratio of GC tissues with undetectable levels of MGMT was significantly higher in $\mathrm{CagA}^{+}$samples than that in $\mathrm{CagA}^{-}$samples $(15 / 22$ vs $4 / 11, p<0.05$; Figure 1D and Table 1). With regard to the relationship between $M G M T$ methylation and MGMT expression, a lower expression level was only observed in those samples showing a high degree of methylation $(P<0.05)$ (Figure 1D-1F).

\section{MGMT hypermethylation and expression loss are recapitulated in CagA plasmid transfected or CagA + HP infected GC cells}

To further investigate the mechanisms underlying the MGMT loss in HP-associated GC, we successfully constructed stable transfectant: CagA-expressing SGC-7901 cell line (CagA+ SGC-7901), pcDNA3.1 empty vector transfected SGC-7901 (EV-SGC-7901) cell line serves as control. HP infected GC cell line SGC-7901 was established using the co-culture method [13]. The methylation status of MGMT was measured by MSP in these cell lines. We found that the MGMT methylation degree indeed increased significantly in the SGC-7901 cell line transfected with CagA plasmid and infected with CagA + HP $(p<0.05)$ (Figure 2A-2B). Further, MGMT expression also markedly decreased in CagA + SGC-7901 and cells infected with $\mathrm{CagA}+\mathrm{HP}(p<0.05)$ (Figure 2C-2D).

\section{CagA induced tumor suppressor genes hypermethylation by upregulating DNMT1}

Since activation of any DNMT protein is considered a potentially significant mean of causing $\mathrm{CpG}$ island methylation in human carcinomas [18], we evaluated the expression of representative DNMT proteins (DNMT1, DNMT3a and DNMT3b) in HP associated GC tissues, CagA transfected and HP cocultured cells respectively. A marked increase of DNMT1 expression was observed in $\mathrm{CagA}^{+} \mathrm{HP}$ infected $\mathrm{GC}$ tissues (Figure $3 \mathrm{~A}-3 \mathrm{C}$ and Table 1), CagA transfected (Figure $3 \mathrm{D}$ and $3 \mathrm{~F}$ ) and $\mathrm{CagA}^{+}$ HP cocultured (Figure $3 \mathrm{E})$ cells $(p<0.05)$. In contrast, no difference in the expression of DNMT3a or DNMT3b was observed in different groups of HP associated tissues and cell lines. To further confirm whether the CagA induced MGMT promoter hypermethylation was dependent on DNMT1 upregulation, we used siRNA or protein inhibitor to inhibit DNMT1, and found that MGMT hypermethylation and MGMT expression reduction could be reversed by DNMT1 siRNA or its specific inhibitor $(5$-aza-cdr) $(p<0.05)$ (Figure 3G). 


\section{CagA enhanced DNMT1 expression via PDK1/ AKT -NFkB pathway}

Till now, no evidence revealed that CagA could act as a transcription factor to regulate gene expression directly, so we presumed that CagA increased DNMT1 expression by disdurbing some key signal pathway in GC. Since AKT has been well known to play a significant role in regulating genes expression and the aforementioned data revealed that P-PDK1 is a known activator and binding partner of AKT [19], also, it's well established that $\mathrm{NF \kappa B}$ is a downstream element of the AKT pathway [20], so we investigated whether PDK1/AKT-NFKB pathway is involved in DNMT1 upregulation and subsequent MGMT hypermethylation. To this end, the total and phosphorylation protein of PDK1/AKT-NFKB pathway in the nucleus and cytoplasm of cells differently treated were detected. Indeed, we found that P-PDK1, P-AKT and $\mathrm{P}-\mathrm{NF} \kappa \mathrm{B}$ expression significantly increased both in CagA transfected and CagA + HP infected cells (Figure 4A-4B), while there was no significant difference of other signal proteins existed between groups.

To elucidate how CagA promoted AKT phosphorylation, we used immunofluorescence or IP analysis
A

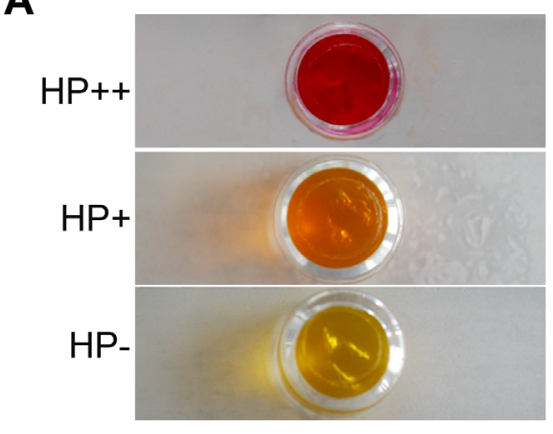

C

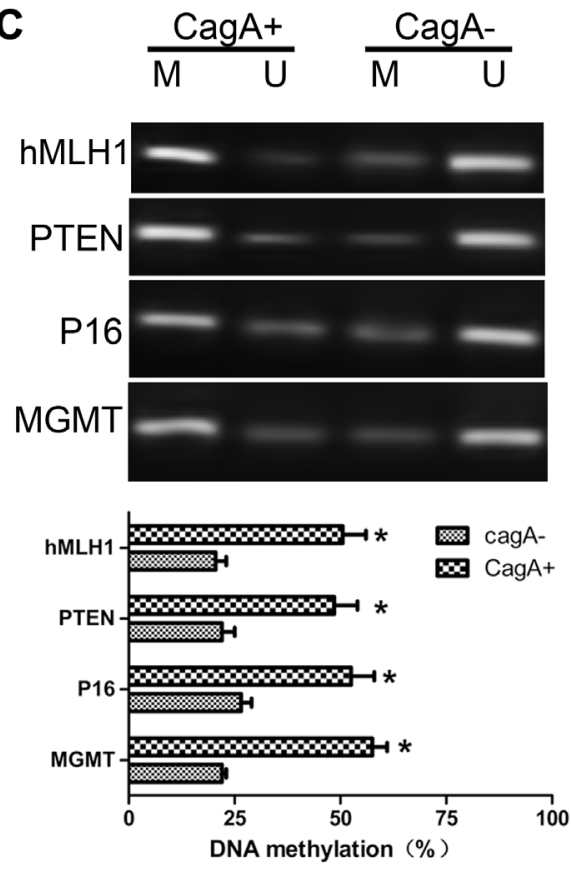

B

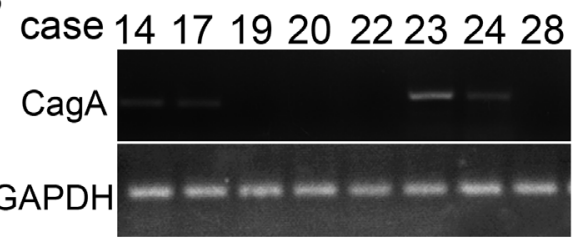

D

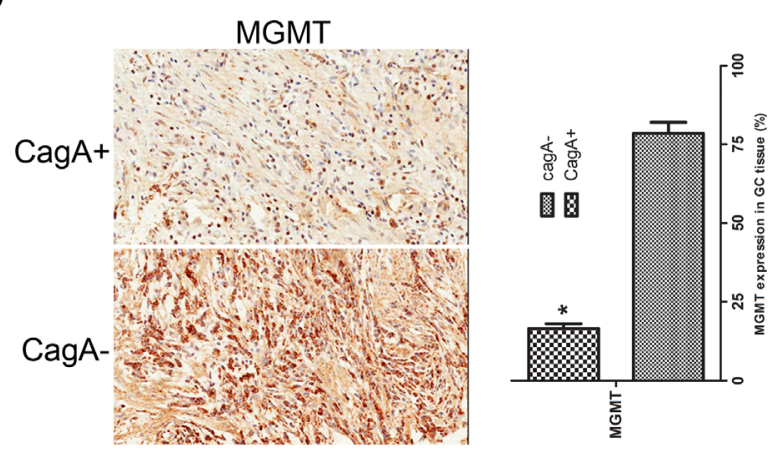

E

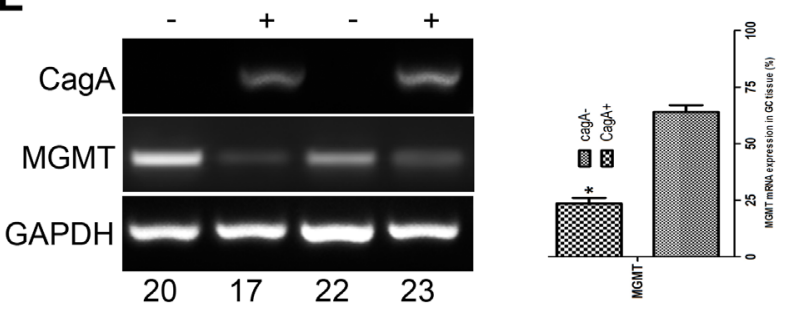

$\mathbf{F}$

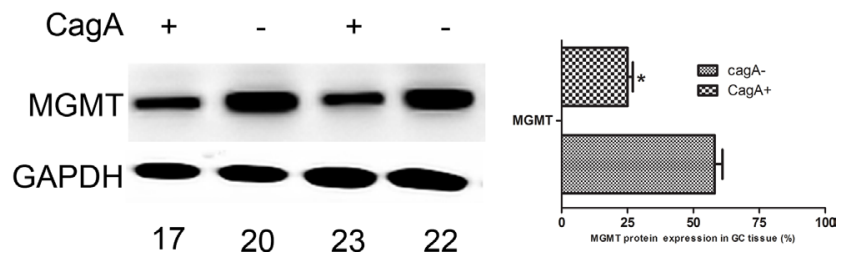

Figure 1: MGMT gene methylation and its expression in HP-associated GC tissues. (A) Rapid urease test (RUT) is used to group clinical tissues into two categories: HP+ (pink and purple) and HP- (yellow). (B) RT-PCR of CagA. HP+ tissues are further subjected to RT-PCR to amplify CagA. HP+ tissues are classified as CagA+ or CagA-. (C) MSP of some conventional cancer suppressor genes including $M G M T$ in HP+ tissues. Gene methylation increases sharply in CagA + tissues compared with CagA- tissues $(p<0.05)$. (D) Immunohistochemical staining of MGMT in HP+ tissues. A notable loss of MGMT is found in CagA+ compared with CagA-tissues. (E and F) mRNA and protein levels of MGMT. RT-PCR and WB are applied to further evaluate MGMT expression. Consistent with results shown in (D), there is a significant difference in MGMT expression between CagA + and CagA- tissues. The graph represents densitometric analysis of the bands obtained for each signal. Results are expressed as the relative expression compared with control cells $\left({ }^{*} p<0.05\right)$. Each value is the mean $\pm \mathrm{SD}$ of three experiments. 
Table 1: Relationship between MGMT expression, MGMT gene methylation, DNMT1 expression and clinicopathologic parameters in GC

\begin{tabular}{|c|c|c|c|c|c|c|}
\hline $\begin{array}{c}\text { Clinicopathologic } \\
\text { Parameters }(n=33)\end{array}$ & $\begin{array}{c}\text { MGMT-MPS } \\
(++/ \pm) n\end{array}$ & $P$ & $\begin{array}{c}\text { MGMT-IHC } \\
(++/ \pm) n\end{array}$ & $P$ & $\begin{array}{c}\text { DNMT1-IHC } \\
(++/ \pm) n\end{array}$ & $P$ \\
\hline \multicolumn{7}{|l|}{$\mathrm{HP}(\mathrm{CagA})$} \\
\hline Positive & $17 / 5$ & 0.009 & $7 / 15$ & 0.031 & $18 / 4$ & 0.049 \\
\hline Negative & $3 / 8$ & & $8 / 3$ & & $5 / 6$ & \\
\hline \multicolumn{7}{|l|}{ Age (years) } \\
\hline$\leq 59$ & $10 / 5$ & $\mathrm{~N}$ & $7 / 8$ & $\mathrm{~N}$ & $12 / 3$ & $\mathrm{~N}$ \\
\hline$>59$ & $10 / 8$ & & $8 / 10$ & & $11 / 7$ & \\
\hline \multicolumn{7}{|l|}{ Gender } \\
\hline Male & $12 / 8$ & $\mathrm{~N}$ & $9 / 11$ & $\mathrm{~N}$ & $13 / 7$ & $\mathrm{~N}$ \\
\hline Female & $8 / 5$ & & $6 / 7$ & & $10 / 3$ & \\
\hline \multicolumn{7}{|l|}{ Bormann Type } \\
\hline $\mathrm{I}-\mathrm{II}$ & $4 / 3$ & $\mathrm{~N}$ & $4 / 3$ & $\mathrm{~N}$ & $6 / 1$ & $\mathrm{~N}$ \\
\hline III-IV & $16 / 10$ & & $11 / 15$ & & $17 / 9$ & \\
\hline \multicolumn{7}{|l|}{ Location } \\
\hline Middle/Proximal & $7 / 5$ & $\mathrm{~N}$ & $5 / 7$ & $\mathrm{~N}$ & $8 / 4$ & $\mathrm{~N}$ \\
\hline Distal & $13 / 8$ & & $10 / 11$ & & $15 / 6$ & \\
\hline \multicolumn{7}{|l|}{ Diameter $(\mathrm{cm})$} \\
\hline$\leq 5$ & $11 / 8$ & $\mathrm{~N}$ & $9 / 10$ & $\mathrm{~N}$ & $13 / 6$ & $\mathrm{~N}$ \\
\hline$>5$ & $9 / 5$ & & $6 / 8$ & & $10 / 4$ & \\
\hline \multicolumn{7}{|l|}{ Histologic type } \\
\hline Intestinal & $8 / 5$ & $\mathrm{~N}$ & $5 / 8$ & $\mathrm{~N}$ & $9 / 4$ & $\mathrm{~N}$ \\
\hline Diffuse & $12 / 8$ & & $10 / 10$ & & $14 / 6$ & \\
\hline \multicolumn{7}{|l|}{ Depth of invasion } \\
\hline $\mathrm{T} 1, \mathrm{~T} 2$ & $6 / 4$ & $\mathrm{~N}$ & $4 / 6$ & $\mathrm{~N}$ & $8 / 2$ & $\mathrm{~N}$ \\
\hline $\mathrm{T} 3, \mathrm{~T} 4$ & $14 / 9$ & & $11 / 12$ & & $15 / 8$ & \\
\hline \multicolumn{7}{|l|}{ Lymph-node metastasis } \\
\hline No & $7 / 4$ & $\mathrm{~N}$ & $5 / 6$ & $\mathrm{~N}$ & $8 / 3$ & $\mathrm{~N}$ \\
\hline Yes & $13 / 9$ & & $10 / 12$ & & $15 / 7$ & \\
\hline \multicolumn{7}{|l|}{ Differentiation } \\
\hline High/Middle & $8 / 4$ & $\mathrm{~N}$ & $5 / 7$ & $\mathrm{~N}$ & $8 / 4$ & $\mathrm{~N}$ \\
\hline Moderate/Low & $12 / 9$ & & $9 / 12$ & & $15 / 6$ & \\
\hline \multicolumn{7}{|l|}{ TNM stage } \\
\hline I-II & $1 / 9$ & 0.000 & $8 / 2$ & 0.020 & $5 / 5$ & $\mathrm{~N}$ \\
\hline III-IV & $19 / 4$ & & $7 / 16$ & & $18 / 5$ & \\
\hline
\end{tabular}

Abbreviation: N, no significant difference.

Statistical significance is assessed using the Pearson $\chi^{2}$ test, Fisher's exact test, or the Mann-Whitney $U$ test. Differences are considered statistically significant in a two-tailed test for $p<0.05$.

and found that P-PDK1/P-AKT interaction in CagA transfected cells increased sharply (Figure 4C-4D). To confirm the correlation between AKT phosphorylation, DNMT1 upregulation and subsequent MGMT hypermethylation, we inhibited AKT activity by its specific inhibitor or siRNAs, and found that DNMT1 expression decreased while MGMT expression subsequently increased in parallel with P-AKT reduction (Figure 5A and 5C). Furthermore, $M G M T$ methylation significantly decreased in parallel with P-AKT reduction $(p<0.05)$ (Figure 5B and 5D). Thus, P-AKT and DNMT1 overexpression closely correlated with $M G M T$ hypermethylation and its expression reduction. Therefore, these results are consistent with the proposal that DNMT1, upregulated by 
CagA in a P-AKT dependent manner, promoted $M G M T$ hypermethylation, leading to MGMT reduction in GC. In order to determine whether NFאB regulated DNMT1 directly, the firefly luciferase reporter constructs containing DNMT1 promoter with NF $\kappa$ B potential target sites was generated (DNMT1-WT/MT1/MT2) and transfected into GC cells, and we found that the luciferase activity increased significantly in cells co-transfected with CagA and DNMT1-WT or DNMT1-MT2 compared with control cells. Consistent with this finding, the luciferase activity was significantly decreased by NFאB inhibitor, SN50, or siRNA. Also, no difference in the luciferase activity between DNMT1-MT2 and DNMT1-WT groups was observed, which indicated that MT2 location may not contain NFкB binding sites (Figure 5E). To confirm these results, we employed ChIP and found that NFאB could bind to the DNMT1 promoter region (Figure 5F). In total, these data strongly suggested that NFאB could up-regulate DNMT1 expression by binding to its promoter directly.

\section{CagA induced DNMT1 up-regulation, subsequent $M G M T$ hypermethylation and MGMT loss via PDK1/AKT-NFкB pathway reoccurred in vivo}

To determine if the above results could be recapitulated in vivo, we performed the following experiment: Six to eight weeks old C57BL/6 mice were orally inoculated once with $1 \times 10^{8}$ CFU HP strain ATCC49503 (CagA+) or ATCC51932 $\left(\mathrm{Cag} \mathrm{A}^{-}\right)$. Control mice were not given bacteria. Mice were sacrificed four months after inoculation and gastric tissues were collected. The mice that had been successfully

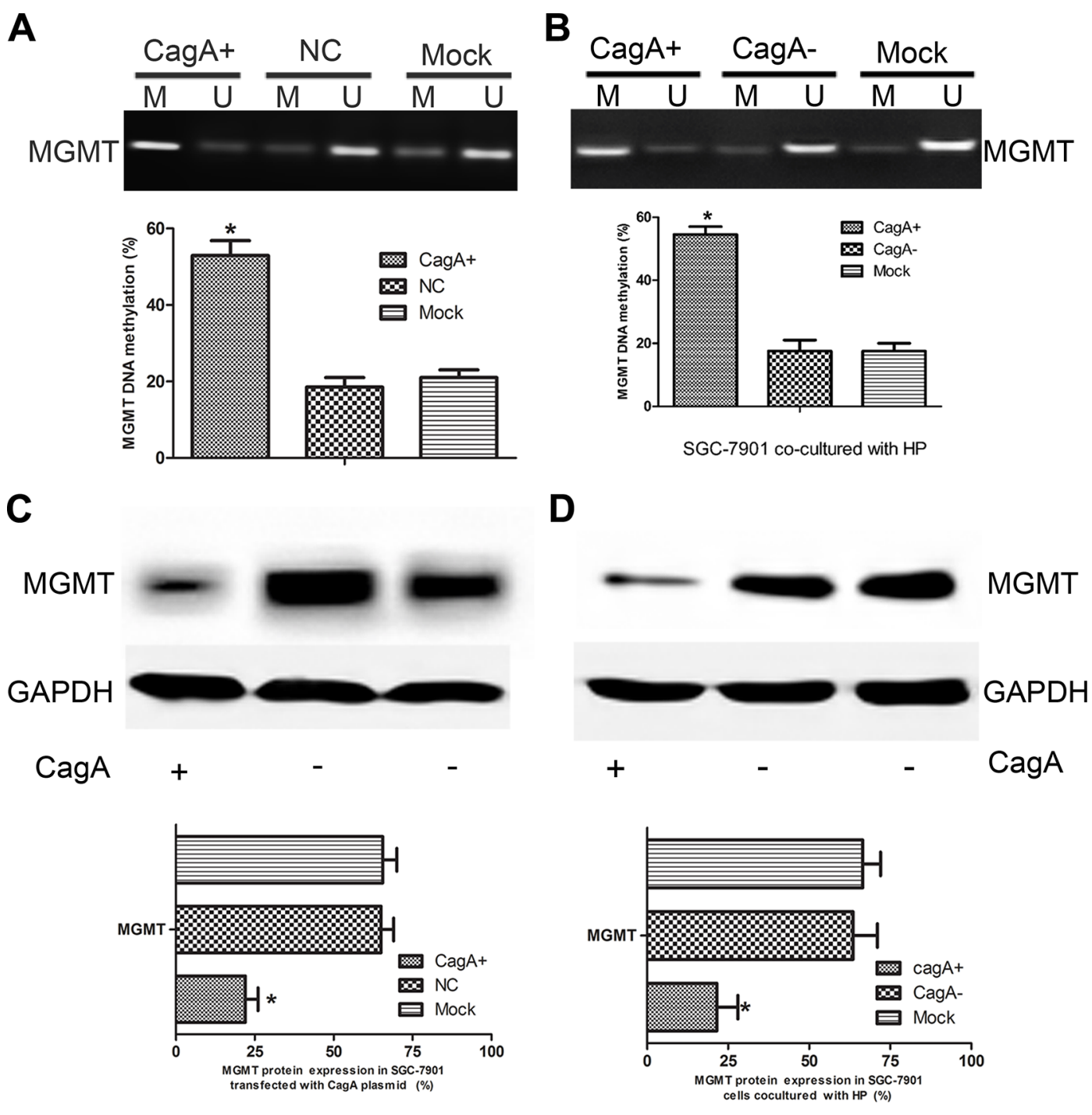

Figure 2: CagA induces MGMT gene hypermethylation and its expression loss. (A and B) $M G M T$ methylation status in CagA+ SGC-7901 and HP-infected cells. Increased MGMT methylation is observed in CagA transfected and CagA+ HP infected cells compared with control groups. (C and D) MGMT expression in CagA stablely transfected and HP cocultured (MOI 100:1) cells detected by WB. MGMT downregulation is observed in CagA stablely transfected and CagA+ HP infected cells compared with control groups. The graph represents densitometric analysis of the bands obtained for each signal. Results are expressed as relative expression compared with control cells $(* p<0.05)$. Each value is the mean $\pm \mathrm{SD}$ of three experiments. 
infected with HP were confirmed by RUT or Giemsa staining (Figure 6A-6B). As observed in clinical tissues, $\mathrm{HP}$ co-cultured and CagA transfected cells, a significant up-regulation of P-PDK1, P-AKT, P-NFkB, or DNMT1 and MGMT down-regulation were observed in vivo $(p<0.05)$ (Figure 6D). In addition, IHC staining showed that DNMT1 expression elevated, which was in accordance with WB results (Figure 6C). We then evaluated the MGMT methylation using MSP, and as shown in Figure 6E, a marked increase in MGMT methylation in tissues infected with CagA $+\mathrm{HP}$ strain was observed compared with CagA- HP strain $(p<0.05)$.
In total thus, our results are consistent with the following model of CagA-mediated aberrant $M G M T$ methylation in GC tissues (Figure 6F): The adherence of HP to gastric epithelia results in the delivery of CagA into the cytoplasm, where it activates AKT via P-PDK1. Subsequently, P-AKT translocates into the nucleus where it activates $\mathrm{NF} \kappa \mathrm{B}$ which upregulates DNMT1. Finally, the increased DNMT1 results in $M G M T$ hypermethylation, causing its reduced expression, which contributes to the initiation and development of GC.
A

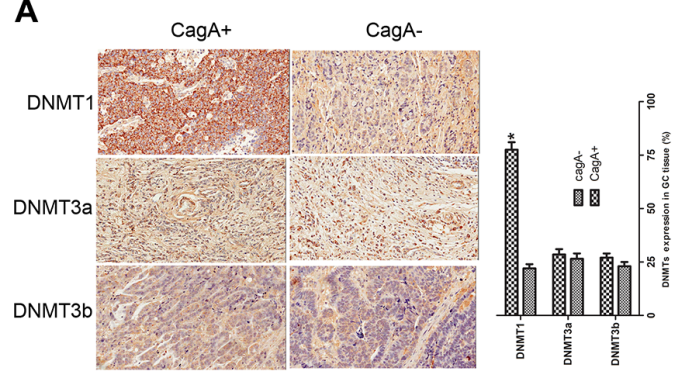

B

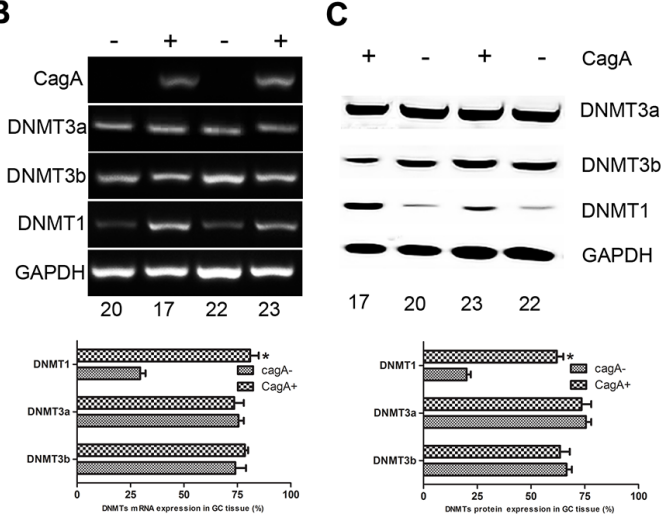

D

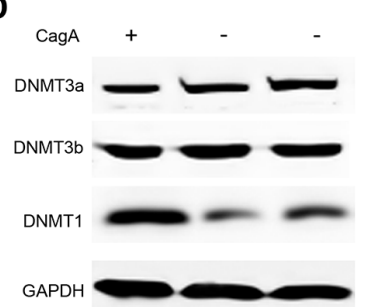

E

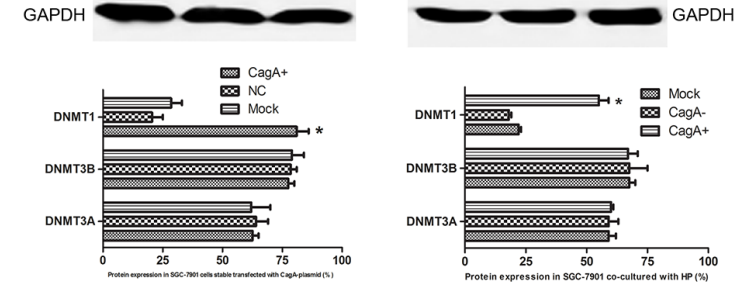

G

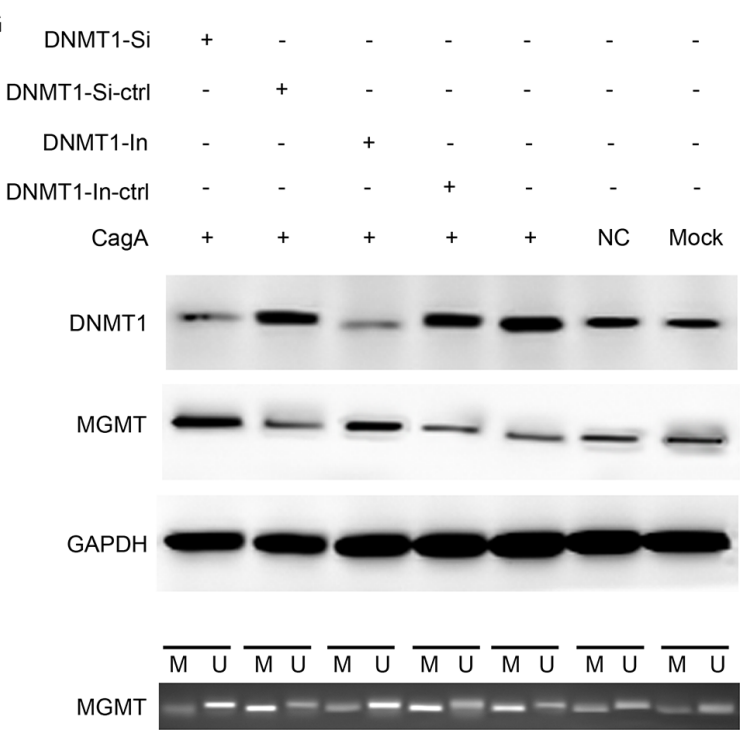

Figure 3: CagA-induced DNMT1 upregulation is responsible for MGMT promoter hypermethylation and its expression loss. (A) Immunohistochemical staining of DNMTs in HP-associated tissues. A marked elevation of DNMT1 is found in CagA+ tissues compared with CagA- tissues, whereas no difference in DNMT3a or DNMT3b expression is observed between groups. (B and C) mRNA and protein expression of DNMTs in HP-associated tissues. Consistent with the results shown in (A), there is a significant difference in DNMT1 expression between CagA+ and CagA- tissues, while DNMT3a or DNMT3b expression remains unchanged in different groups. (D and E) DNMTs expression in CagA+ cells and HP cocultured cells analysed by WB. A remarkable DNMT1 upregulation is found in CagA+ cells and HP cocultured cells compared with control groups while no difference of DNMT3a and DNMT3b exists between groups. (F) Immunocytochemical analysis of DNMT1 expression in CagA+ SGC-7901. A much stronger positive reaction is confirmed in CagA+ cells compared with control groups. (G) MGMT hypermethylation is reversed by DNMT1 inhibition. (UP) DNMT1 and MGMT expression is reversed by siRNA or inhibitor (5-aza-cdr) of DNMT1. (DOWN) MGMT hypermethylation is reversed by DNMT1 siRNA or its inhibitor. The graph represents densitometric analysis of the bands obtained for each signal. Results are expressed as relative expression compared with control cells $(* p<0.05)$. Each value is the mean $\pm \mathrm{SD}$ of three experiments. 


\section{DISCUSSION}

A causal relationship between HP and GC is first postulated by Marshall and Warren in 1983 [1]. More and more data shows that oncoprotein CagA is the most important molecule among HP virulent factors, upon HP attachment to the epithelial cell, the CagA is injected directly into the cell via the TFSS [5]. CagA then localizes to the plasma membrane inner surface, where it undergoes tyrosine phosphorylation by Src family kinases (SFK) such as c-Src [21]. Accordingly, upon phosphorylation, CagA disturbs signal transduction, and thereby provokes cellular dysfunction that eventually leads to cell transformation [22].

Carcinomas showing a high degree of tumor suppressor gene $\mathrm{CpG}$ island methylation are referred to as a $\mathrm{CpG}$ island methylator phenotype (CIMP), which is the most characteristic among genetic and epigenetic abnormalities in HP-associated GC [23]. Niwa et al.

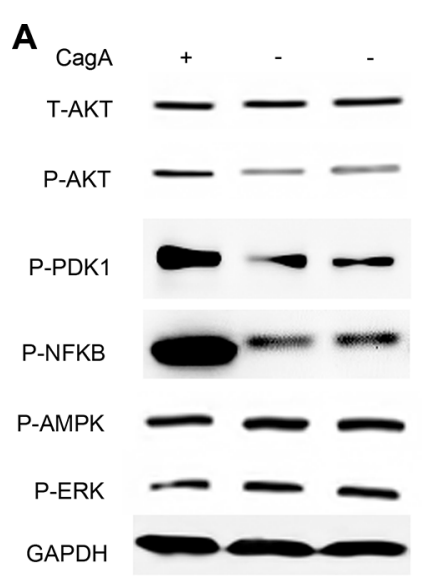

C
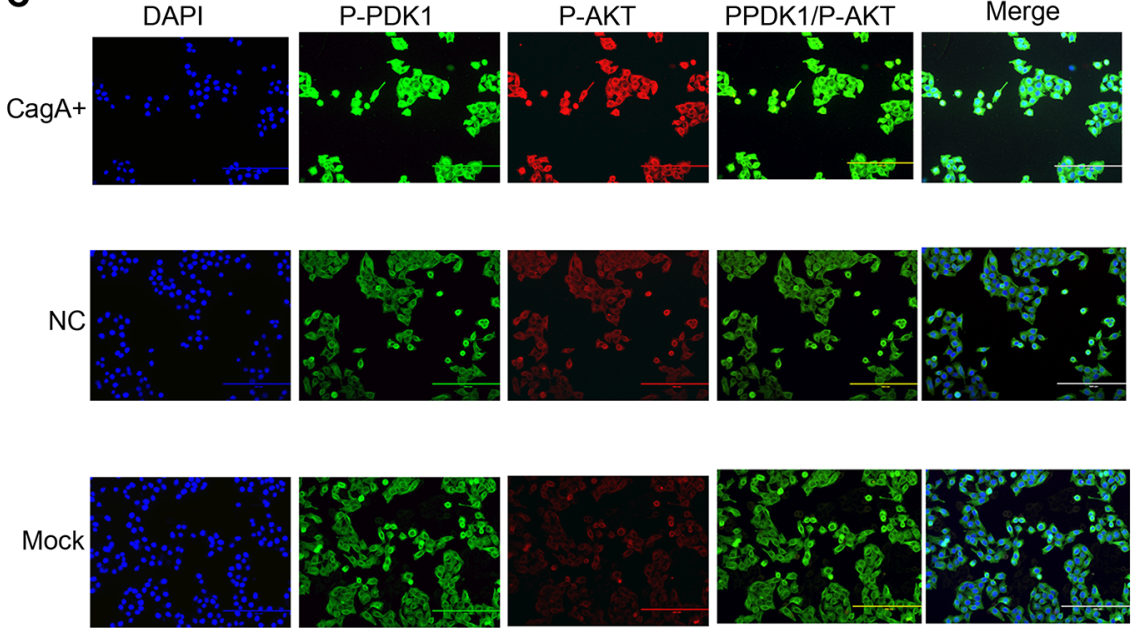

D
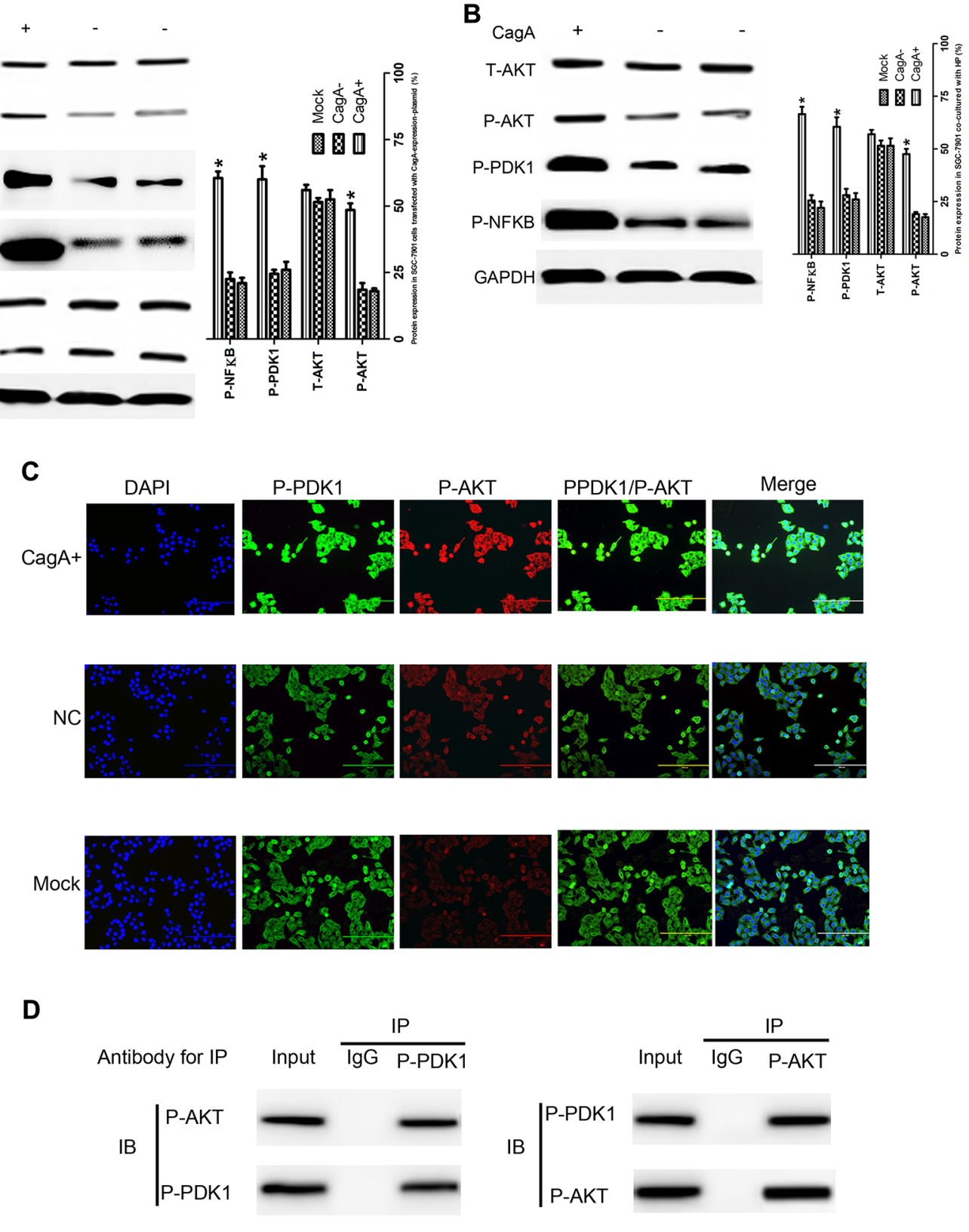

Figure 4: CagA activates AKT-NFкB pathway by enhancing the interaction of P-PDK1 and P-AKT. (A and B) GC related signal proteins expression in differently treated cells detected by WB. P-PDK1/P-AKT/P-NFKB increases in CagA transfected or HP (MOI 100:1) cocultured cells compared with control cells. (C) Co-localization of P-PDK1 and P-AKT. The intracellular co-localization of P-PDK1 and P-AKT is analyzed using immunofluorescence microscopy. The overlay is indicated by yellow color. Data shows that the CagA group has a strong yellow signal which representes tightly interaction of P-PDK1 and P-AKT. (D) The IP test confirms the interaction of P-PDK1 and P-AKT. Data shows that P-PDK1 and P-AKT protein could be precipitated by mutual antibodies. These data suggest that CagA enhances the interaction of P-PDK1 and P-AKT. The graph represents densitometric analysis of the bands obtained for each signal. Results are expressed as relative expression compared with control cells $\left({ }^{*} p<0.05\right)$. Each value is the mean $\pm \mathrm{SD}$ of three experiments. 
showed specific types of chronic inflammation (HP infection) are necessary for methylation patterns changes [24].Tumor suppressor genes methylation that occurs in a number of mucosa cells establishes an 'epigenetic field for cancerization' or an 'epigenetic field defect', which distinguishes a site as a high risk for subsequent malignant transformation[25]. Previous study has noted that methylated MGMT is significantly associated with CagA+ HP infection $(p<0.035)$ [14]. Consistent with this, in this study, we found that the MGMT gene represents an example of this typical feature. MGMT promoter methylation and MGMT expression repression were observed concurrently in CagA-associated GC tissues,
GC cell lines stablely transfected with CagA or infected with $\mathrm{CagA}^{+} \mathrm{HP}$.

Almost all of the East Asian HP strains are cag-PAI-positive [3]. There is compelling evidence to support the importance of HP in inducing tumor suppressor genes methylation in GC development but less is known about the mechanisms. The key enzymes mediated hypermethylation mainly include DNMTs [17]. Our data shows that DNMT1 upregulation positively correlated with CagA in GC specimens. And there is growing evidence that many kinds of viral proteins could regulate DNMT1 expression via different signal pathways [26-28]. EBV- LMP2A activates DNMT1 transcription
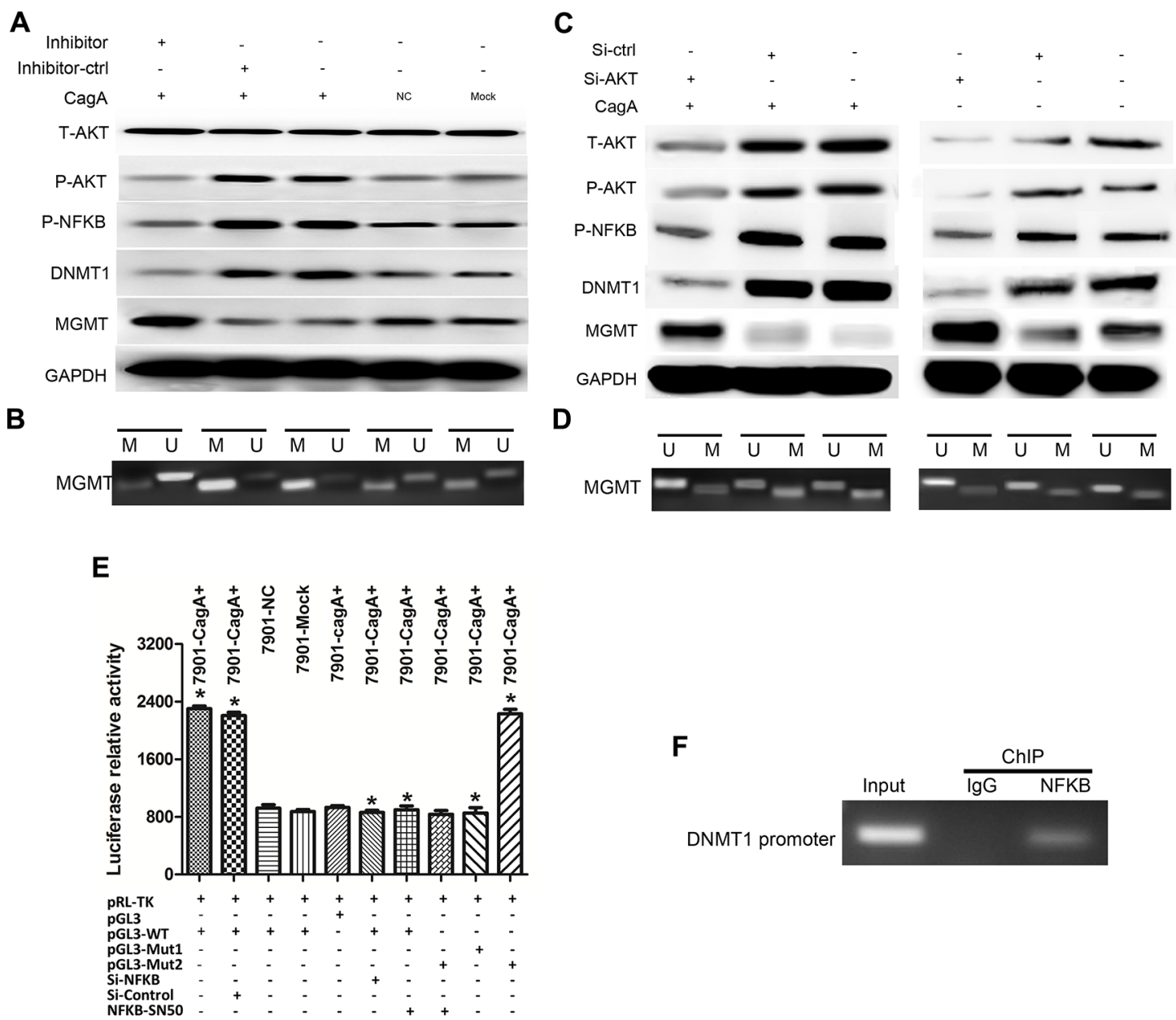

Figure 5: CagA-mediated DNMT1 upregulation is dependent on constitutive AKT phosphorylation and subsequent activated NFкB which combines to DNMT1 promoter. (A and C) WB analysis of related signal proteins in different groups after treated with AKT inhibitor (MK-2206 2HC) or AKT siRNAs. MGMT reduction in CagA+ SGC-7901 is reversed by AKT inhibitor or AKT siRNAs, On the other hand, T-AKT, P-PDK1/P-AKT/P-NFKB and DNMT1 expression significantly decrease in CagA+ cells compared with control cells. (B and D) MSP analysis of MGMT methylation in CagA+ SGC-7901 or EV-SGC-7901 after AKT inhibiton. MGMT hypermethylation is also markedly reversed in CagA+ SGC-7901 by AKT inhibitor or AKT siRNAs compared with control cells. (E) Reporter plasmids of DNMT1 (pGL3-DNMT1) are generated by ligating DNMT1 promoter region into the pGL3-basic vector. CagA transfection significantly increases luciferase activity, which is significantly reduced by NFKB inhibition. (F) DNMT1 promoter region and NFkB interaction is validated by the ChIP. Data shows that DNMT1 DNA is detectable in the ChIP sample of CagA+ SGC-7901 using an

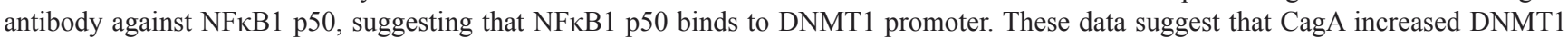
expression may depend on $\mathrm{NF \kappa B}$ activation. Results are expressed as relative expression compared with control cells $\left({ }^{*} p<0.05\right)$. Each value is the mean $\pm \mathrm{SD}$ of three experiments. 
A

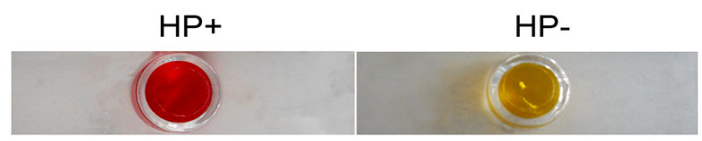

B

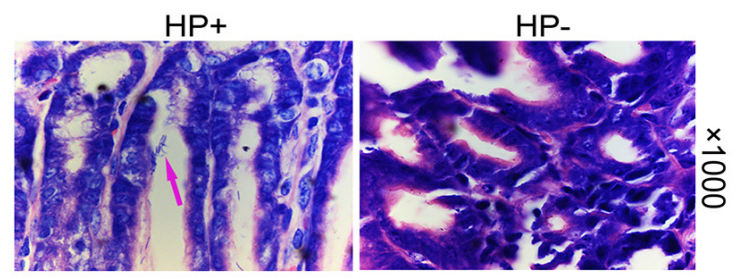

C
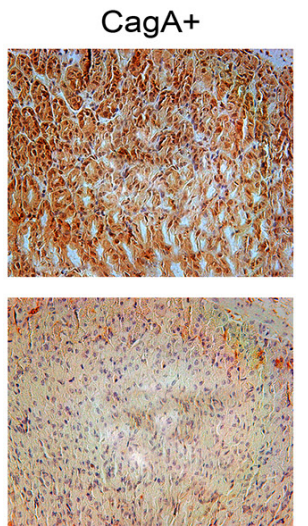

Mock

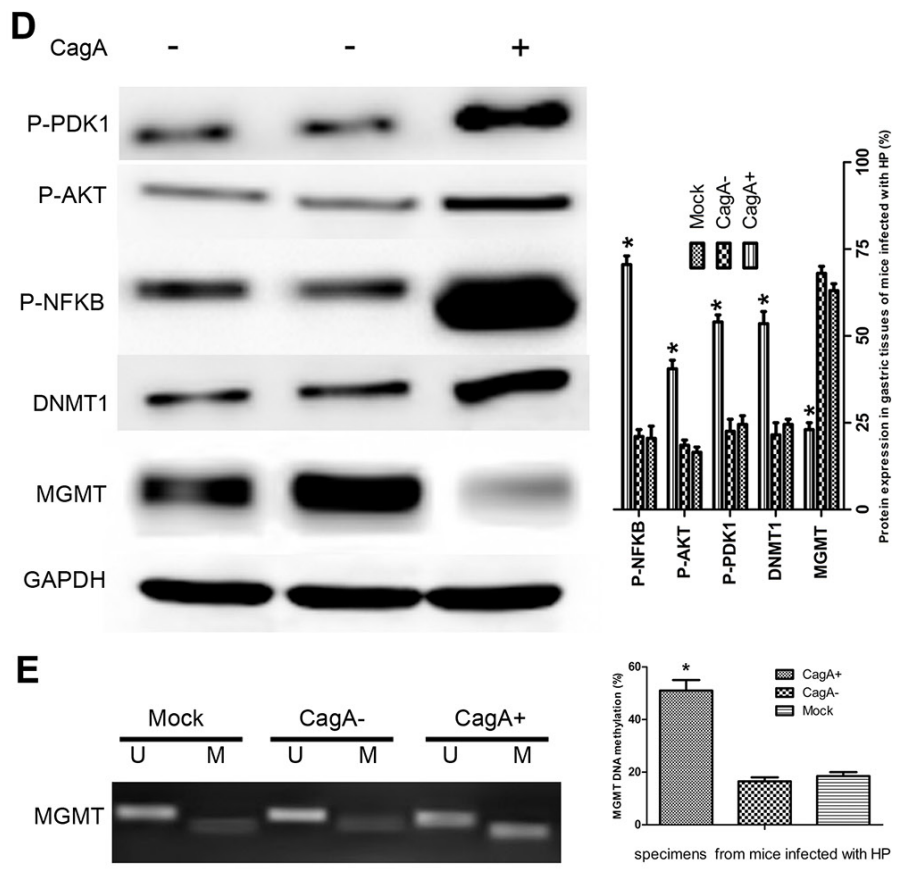

$\mathbf{F}$

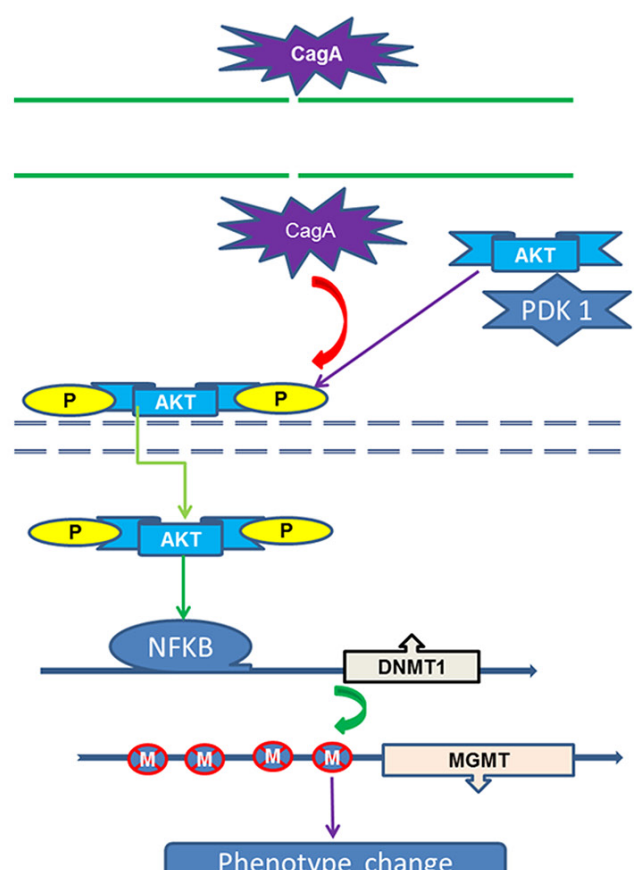

Figure 6: CagA-mediated MGMT hypermethylation and subsequent protein decrease by upregulating DNMT1 via PDK1/AKT-NFKB pathway is recapitulated in vivo. (A and B) RUT and Giemsa staining validates the successful HP colonization in C57BL/6 mice. (C) IHC staining of gastric tissues from mice infected with different HP strains. A marked DNMT1 elevation occurs in CagA+ HP infected tissues compared with control group. (D) WB analysis of related protein expression in mouse gastric tissues infected with different HP strains. A notable MGMT loss paralleled with a significant increase in P-PDK1/P-AKT/P-NFkB/DNMT1 expression is observed in CagA $+\mathrm{HP}$ infected tissues compared with control groups. (E) MSP analysis MGMT methylation in gastric tissues from mice infected with different HP strains. A significant increase in MGMT methylation is observed in CagA + HP infected tissues compared with control groups, which is consistent with what has been confirmed in vitro. (F) Signal pathway schematic diagram. CagA is delivered into the cytoplasm by a type IV secretion system of the adhered HP. CagA then causes an increase in AKT phosphorylation by activating PDK1, subsequently, activated P-AKT translocates into the nucleus where it upregulates DNMT1 by activating NFKB. The upregulated DNMT1 further promotes MGMT hypermethylation, which leads to MGMT loss. The graph represents densitometric analysis of the bands obtained for each signal. Results are expressed as relative expression compared with control cells $(* p<0.05)$. Each value is the mean $\pm \mathrm{SD}$ of three experiments. 
and causes a reduction of PTEN expression through $\mathrm{CpG}$ island methylation of the PTEN promoter in GC [29]. The hypermethylation of the PTEN promoter was also observed in our study (Figure 1C). It has been shown that $p 16$ inactivation induced by $\mathrm{CpG}$ islands methylation could be gradually restored within about 2 weeks after treatment with a DNMT1 inhibitor or after HP eradication [30]. To clarify the mechanism of $\mathrm{CpG}$ island methylation, we utilized HP-infected and CagA stably transfected GC cell lines. In this way, CagA proved to be responsible for the upregulation of DNMT1 in stomach epithelial cells. The intracellular function of CagA and its modulation of signaling pathways of hypermethylation have not yet been fully clarified in GC.

Till now, no data shows that CagA could act as a transcpription factor to regulate gene expression directly, so we presumed that CagA increased DNMT1 via some key signaling pathways, such as AKT-NFkB [31]. Our data clearly showed that AKT phosphorylation significantly increased with CagA expression or HP stimulation, which is consistent with a recent study [31]. Further, we found that CagA could activate PDK1, an essential component in the activation of AKT, and strengthen its interaction with AKT as a key downstream molecule of the AKT pathway, NFKB plays an important role in carcinogenesis [20]. We thus evaluated the function of NFאB in DNMT1 up-regulation induced by CagA, and found that $\mathrm{NF} \kappa \mathrm{B}$ could indeed be activated following AKT phosphorylation. Moreover, we showed that NFKB directly promoted the DNMT1 expression after activation by CagA. Our findings suggest that CagA induced MGMT hypermethylation by upregulating DNMT1 dependent on PDK1/AKT-NFKB pathway, which was confirmed in vivo. Further studies are necessary to determine to what extent the CagA-AKT-NFkB-DNMT1 pathway contributes to the global $\mathrm{CpG}$ island methylation of tumor suppressor genes in HP-associated GC in vivo and what conditions make it specific among other AKT targets.

In conclusion, this study has shown that CagA induced the phosphorylation of AKT by enhancing its interaction with PDK1, which then led to DNMT1 overexpression via $\mathrm{NF} \kappa \mathrm{B}$ activation. We speculate that this increased methylation activity leads to an accumulation of tumor suppressor hypermethylation, such as MGMT, eventually surpassing a threshold whereby the normal integrity of stomach epithelial cells is compromised and thus playing a significant role in the overall GC development.Thus, CagA-AKT/NFkB-DNMT1 pathway maybe a potential therapy target of $\mathrm{HP}$-associated GC.

\section{MATERIALS AND METHODS}

\section{Tissues and cell lines}

Tumor tissues and its paired adjacent non-tumor tissues of GC were collected from the patients underwent radical gastrectomy for GC at Ruijin Hospital between
2012 and 2014. Tissue slices were taken from 10\% formalin-fixed, paraffin-embedded tissue blocks. All GC cases were histologically diagnosed according to the Japanese Classification of Gastric Carcinoma and Lauren's classification [32, 33]. Human GC cell line SGC-7901 was purchased from Shanghai Institutes for Biological Sciences, Chinese Academy of Sciences. The cells were cultured routinely in RPMI-1640 supplemented with 10\% heat-inactivated fetal bovine serum (FBS), $100 \mathrm{U} / \mathrm{ml}$ penicillin and $100 \mu \mathrm{g} / \mathrm{ml}$ streptomycin in a humidified cell incubator with an atmosphere of $5 \% \mathrm{CO}_{2}$ at $37^{\circ} \mathrm{C}$. Exponentially growing cells were used for experiments.

\section{H. pylori strains and cell co-culture}

H pylori bacterial strains 60190 ((ATCC 49503, CagA + ) and Tx30a (ATCC 51932, CagA-) were got from American Type Culture Collection. Bacteria were routinely cultured on $5 \%$ horse blood agar plates (Oxoid Ltd, Basingstoke, UK) in humidified incubators, which provided an atmosphere of $5 \% \mathrm{CO}_{2}$ at $37^{\circ} \mathrm{C}$. GC cells were trypsinized, resuspended in normal growth medium and seeded into 6 well plates. Three duplicate wells were prepared for each experimental condition. When the cells reached $70 \%$ confluence they were serum-starved for $24 \mathrm{~h}$ prior to the addition of HP at a multiplicity of infection of 100. Cells were co-cultured with the bacteria for $24 \mathrm{~h}$ before either RNA or DNA extraction or protein measurements were performed.

\section{Detection of HP infection}

Rapid Urease Test (RUT) and Giemsa staining were employed for detecting HP infection. The presence of HP in tissues was evaluated using a RUT-targeting HP- encoded urease kit(Shanghai Hui Tai Medical Science and Technology Co., Ltd). If the gel became pink, red or dark red within $5 \mathrm{~min}$, this signified a positive result, and it's a negative result if the gel remained yellow. Giemsa staining was carried out according to the manufacturer's instructions (Gibco, CA, USA). HP infection was diagnosed as positive if one of the methods produced positive result.

\section{Establishment of stable transfectants}

The CagA plasmid was prepared from the amplified product of HP CagA gene. After digestion with SpeI and HindIII, the restricted fragment was inserted into pcDNA3.1 vector which was purchased from NOVOBIO. Cells were plated at a density of $2 \times 10^{5}$ cells $/ \mathrm{cm}^{2}$, cultured for $24 \mathrm{~h}$ and then stably transfected with CagA pcDNA3.1 or empty pcDNA3.1 vectors. After $24 \mathrm{~h}$, and every $48 \mathrm{~h}$ thereafter for 4 weeks, culture medium was replaced with fresh medium containing $800 \mu \mathrm{g} / \mathrm{ml}$ of G418. Pools of 16 clones were isolated as stable transfectants with a CagA 
vector (CV) and an empty vector (EV) in SGC-7901 cells. Individual clones were isolated for further study.

\section{Immunohistochemistry (IHC), western blotting (WB) and immunocytochemistry (ICC)}

For IHC, sections were de-waxed using three changes of xylene for $4 \mathrm{~min}$ each and microwave heated to $98^{\circ} \mathrm{C}$ for 15 min (EMS900, Electron Microscopy Sciences, Hatfield, PA, USA) in citric acid buffer ( $\mathrm{pH}$ 6.0), then incubated with primary antibodies (Abcam, Cambridge, UK) for $1 \mathrm{~h}$. Secondary (Dako) antibodies were applied for another hour following the removal of the primary antibodies. Staining was developed with an avidin biotinylated horseradish peroxidase complex and DAB (Dako). Expression of MGMT, DNMT1, DNMT3a and DNMT3b was detected in both the cytoplasm and nucleus and they were considered overexpression if more than $15 \%$ cells were stained positive. For WB, following trypsinization, cell pellets were washed with PBS and cell extracts were prepared using sonication in $50 \mathrm{mM}$ Tris-HCl buffer $(\mathrm{pH}$ 8.0) containing $1 \%$ glycerol, $1 \mathrm{mM}$ EDTA, $0.5 \mathrm{mM}$ PMSF and $2 \mathrm{mM}$ benzamidine followed by centrifugation. Equal protein amounts $(100 \mu \mathrm{g})$ were electrophoresed on $12 \%$ reducing SDS-polyacrylamide gels. Proteins were electrotransferred to Immobilon-P membranes. Membranes were blocked with 5\% non-fat dry milk in Tris-buffered saline (TBS; pH 8.0) containing $0.1 \%$ Tween- 20 for $2 \mathrm{~h}$, and subsequently incubated with primary antibodies (Abcam, Cambridge, UK) at $1 \mu \mathrm{g} / \mathrm{ml}$. Antigen-antibody complexes were visualized using enhanced chemiluminescence. Band intensities were quantitated using a Tanon 2500 imaging system (TANON). For ICC, cells were grown in 6-well plates containing sterile cover slips. When cells reached $\leq 80 \%$ confluence, the medium was removed from and cells were fixed in $2 \%$ paraformaldehyde for $20 \mathrm{~min}$ before they were permeabilized with $0.1 \%$ Triton-X100 for $5 \mathrm{~min}$ and blocked for $1 \mathrm{~h}$ at room temperature. The primary antibody was applied (dilution 1:200) on cells and incubated at $4{ }^{\circ} \mathrm{C}$ overnight. The next day, secondary antibodies were applied for another hour after the primary antibodies removal. Staining was developed with DAB. Cells were washed with $1 \times$ PBST between steps.

\section{Immunofluorescence analysis}

Cells on coverslips were washed twice with PBS and fixed in $2 \%$ paraformaldehyde at room temperature for 15 min. Cell Permeabilization was performed with $0.1 \%$ Triton in PBS at $4^{\circ} \mathrm{C}$ for $10 \mathrm{~min}$. The cells were blocking with $2 \% \mathrm{BSA}$ at room temperature for $1 \mathrm{~h}$, and rinsed three times with PBS before incubated with primary antibody at $4^{\circ} \mathrm{C}$ overnight. Cells were incubated with a secondary antibody for $2 \mathrm{~h}$ before immunofluorescence detection. Nucleus was stained with DAPI for 3 min. Images were acquired using an immunofluorescence microscopy (Olympus) equipped with $20 \times$ objective.

\section{Immunoprecipitation}

Immunoprecipitation was employed using a co-IP kit (Pierce) as the manufacturer's instructions. Cells were lysed at $4^{\circ} \mathrm{C}$ in $50 \mathrm{mmol} / \mathrm{L}$ Tris- $\mathrm{HCl} \mathrm{pH}=7.5,150$ $\mathrm{mmol} / \mathrm{L} \mathrm{NaCl}, 1 \%$ Brij-96, 0.1\% sodium dodecyl sulfate, $10 \mathrm{mmol} / \mathrm{L} \mathrm{NaF}, 5 \mathrm{mmol} / \mathrm{L} \mathrm{VO} 4$, and protease inhibitors. $300 \mu \mathrm{g}$ proteins were incubated with $3 \mu \mathrm{g}$ primary antibodies at $4^{\circ} \mathrm{C}$ overnight. Immune complexes were precipitated with protein $\mathrm{A} / \mathrm{G}$ sepharose beads and washed extensively before WB analysis.

\section{Luciferase reporter assay}

We analyzed DNMT1 promoter region for the potential NFkB binding site using the web sites (http:// alggen.lsi.upc.es/cgi-bin/promo_v3/promo/promoinit. cgi?dirDB=TF 8.3 and http://jaspar.genereg.net/). The promoter of human DNMT1 gene was cloned into the pGL3 reporter plasmid (Ambion), obtaining the WT firefly luciferase reporter gene. Overlap extension PCR was applied to introduce mutations into the seed sequences of NFкB binding sites and generate the DNMT1 MT1 and MT2 reporter genes, which mutated at positions -856 to -867 and -1103 to -1114 , respectively. Cells seeded onto 24-well plates were co-transfected with firefly reporter constructs containing the DNMT1 promoter, Renilla expressing plasmid, pRL-TK, and CagA plasmid or control plasmid using Lipofectamine 2000. Firefly luciferase activity and Renilla luciferase activity were measured $24 \mathrm{~h}$ after the initiation of transfection by the Dual Luciferase Asssay Systems (Promega). Firefly luciferase activity was normalized to Renilla luciferase activity.

\section{Chromatin immunoprecipitation (ChIP) assay}

To evaluate the effect of CagA on the interaction between NFKB and DNMT1 promoter region, ChIP was performed as the manufacturer's instructions (millipore). Cells were fixed with formaldehyde for protein/DNA crosslinking and lysed. The DNA was sheared by sonication (15 pulses, $35 \mathrm{sec}$ on $35 \mathrm{sec}$ off) and added to a well coated with the anti-NFkB (Abcam). Washes were performed to remove unbound material, while NFKB-bound DNA was released by protein digestion with proteinase $\mathrm{K}$. The DNA was purified through a column and PCR was performed using primers designed to target the DNMT1 promoter region spanning the site of interaction with $\mathrm{NF \kappa B}$, while genomic DNA and IgG were used as control.

\section{DNA extraction, methylation-specific PCR (MSP), RNA isolation and RT-PCR}

Genomic DNA was isolated using a QIA-amp DNA Mini Kit (QIAGEN) according to the manufacturer's instructions. MGMT methylation status was determined using a bisulfite modification and MSP assay with the 
Epi-Tect Bisulfite Kit and Epi-Tect MSP Kit (QIAGEN). The products were run on a $2 \%$ agarose gel and analyzed with DNA-GREEN staining. RNA was extracted with TRIzol reagent (Invitrogen) and $1 \mu \mathrm{g}$ RNA was reverse transcribed using an oligo (dT) primer and RTAMV reverse transcriptase (Invitrogen, Carlsbad, CA). The resulting cDNA was amplified under the following conditions: $2 \mathrm{~min} 95^{\circ} \mathrm{C}$ for the first cycle; $95^{\circ} \mathrm{C}$ for $1 \mathrm{~min}$, $60^{\circ} \mathrm{C}$ for $55 \mathrm{~s}$, and $72^{\circ} \mathrm{C}$ for $2 \mathrm{~min}$ for the next 35 cycles; and a final elongation step at $72^{\circ} \mathrm{C}$ for $10 \mathrm{~min}$. RT-PCR products were separated using electrophoresis on a $1.5 \%$ agarose gel stained with DNA-GREEN (PCR grade), and visualized using UV light.

\section{Plasmid and siRNA transfection and inhibitor application}

siRNA (750 pmol) (Santa Cruz, CA, USA) was transfected into cells $\left(2 \times 10^{6}\right)$ using the Lip2000. After transfection, cells were cultured in RPMI-1640 supplemented with 10\% heat-inactivated FBS. Plasmid DNA and lipofectamine were diluted separately in serumfree medium and incubated at room temperature for $5 \mathrm{~min}$. After incubation, the diluted DNA and Lipofectamine were mixed and incubated at room temperature for $20 \mathrm{~min}$. Aliquots of the transfection mixture were added to each well of the cell culture plate. Inhibitors were used as follows: MK-2206 2HC (Selleck) $15 \mathrm{nM}$ for AKT, 5-aza-cdr (Sigma)

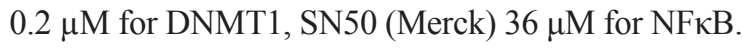

\section{HP infection in vivo}

Six to eight-week-old C57BL/6 mice (Institute of Zoology, Chinese Academy of Sciences, Shanghai, China) were inoculated orally once with $1 \times 10^{8} \mathrm{CFU}$ of brothcultured HP strains $60190(\mathrm{CagA}+)$ or Tx30a $(\mathrm{CagA}-)$, in $0.15 \mathrm{ml}$ broth. Control mice were given PBS. Mice were sacrificed four months after inoculation and gastric tissues were collected for HE, RT-PCR, WB and MSP analysis.

\section{Ethics statement}

All animal experiments described in this article were conducted according to China guidelines for animal experimentation and approved by the Institutional Animal Care Committee of Ruijin Hospital affliated Shanghai JiaoTong University School of Medicine. All patients provided written informed consent before enrollment and the Ethic Committee of Ruijin Hospital Shanghai Jiao-Tong University School of Medicineapproved the study protocol.

\section{Statistical methods}

Statistical analyses were performed using a Student's $t$-test or one-way ANOVA, the chi-squared test, Fisher's exact test or the Mann-Whitney $U$ test.
Differences were considered statistically significant in a two-tailed test for $p$-values $<0.05$. The statistical analysis software used was SPSS Version 19.0.

\section{ACKNOWLEDGMENTS}

We thank D. M. Czajkowsky for useful discussions.

\section{FUNDING}

This study was supported by grants from National Natural Science foundation of China (No.91529302, No.81572798, No. 81272749) and Key Projects in the National Science \& Technology Pillar Program of China (No. 2014BAI09B03), and Shanghai Health Bureau No.2012306.

\section{CONFLICTS OF INTEREST}

There no potential conflicts of interest to declare.

\section{REFERENCES}

1. Marshall B, Warren JR. Unidentified curved bacilli in the stomach of patients with gastritis and peptic ulceration. The Lancet. 1984; 323:1311-1315.

2. Uemura N, Okamoto S, Yamamoto S, Matsumura N, Yamaguchi S, Yamakido M, Taniyama K, Sasaki N, Schlemper RJ. Helicobacter pylori infection and the development of gastric cancer. New Engl J Med. 2001; 345:784-789.

3. Slater E, Owen RJ, Williams M, Pounder RE. Conservation of the cag pathogenicity island of Helicobacter pylori: Associations with vacuolating cytotoxin allele and IS 605 diversity. Gastroenterology. 1999; 117:1308-1315.

4. You Y, He L, Zhang M, Fu J, Gu Y, Zhang B, Tao X, Zhang J. Comparative genomics of Helicobacter pylori strains of China associated with different clinical outcome. PLoS One. 2012; 7:e38528.

5. Odenbreit S, Püls J, Sedlmaier B, Gerland E, Fischer W, Haas R. Translocation of Helicobacter pylori CagA into gastric epithelial cells by type IV secretion. Science. 2000; 287:1497-1500.

6. Backert S, Ziska E, Brinkmann V, Zimny-Arndt U, Fauconnier A, Jungblut PR, Naumann M, Meyer TF. Translocation of the Helicobacter pylori CagA protein in gastric epithelial cells by a type IV secretion apparatus. Cell Microbiol. 2000; 2:155-164.

7. Saadat I, Higashi H, Obuse C, Umeda M, MurataKamiya N, Saito Y, Lu H, Ohnishi N, Azuma T, Suzuki A. Helicobacter pylori CagA targets PAR1/MARK kinase to disrupt epithelial cell polarity. Nature. 2007; 447:330-333.

8. Esteller M. Epigenetics in cancer. New Engl J Med. 2008; 358:1148-1159. 
9. Jones PA, Baylin SB. The epigenomics of cancer. Cell. 2007; 128:683-692.

10. Kang GH. CpG island hypermethylation in gastric carcinoma and its premalignant lesions. Korean journal of pathology. 2012; 46:1-9.

11. Kang GH, Lee S, Kim J-S, Jung H-Y. Profile of aberrant $\mathrm{CpG}$ island methylation along multistep gastric carcinogenesis. Lab Invest. 2003; 83:519-526.

12. Natarajan A, Vermeulen S, Darroudi F, Valentine MB, Brent TP, Mitra S, Tano K. Chromosomal localization of human O6-methylguanine-DNA methyltransferase (MGMT) gene by in situ hybridization. Mutagenesis. 1992; 7:83-85.

13. Chan AO, Lam S, Wong BC, Wong W, Yuen M, Yeung Y, Hui W, Rashid A, Kwong Y. Promoter methylation of E-cadherin gene in gastric mucosa associated with Helicobacter pylori infection and in gastric cancer. Gut. 2003; 52:502-506.

14. Sepulveda AR, Yao Y, Yan W, Park DI, Kim JJ, Gooding W, Abudayyeh S, Graham DY. CpG Methylation and Reduced Expression of $\mathrm{O}^{6}$-Methylguanine DNA Methyltransferase Is Associated With Helicobacter pylori Infection. Gastroenterology. 2010; 138:1836-1844. e1834

15. Ushijima T, Nakajima T, Maekita T. DNA methylation as a marker for the past and future. J Gastroenterol. 2006; 41:401-407.

16. Zhang Y, Chen F, Sun Y, Zhou S, Li T, Chen R. Effects of DNMT1 silencing on malignant phenotype and methylated gene expression in cervical cancer cells. J Exp Clin Cancer Res. 2011; 30:98.

17. Ben Gacem R, Hachana M, Ziadi S, Ben Abdelkarim S, Hidar S, Trimeche M. Clinicopathologic significance of DNA methyltransferase $1,3 \mathrm{a}$, and $3 \mathrm{~b}$ overexpression in Tunisian breast cancers. Hum Pathol. 2012; 43:1731-1738.

18. Girault I, Tozlu S, Lidereau R, Bièche I. Expression analysis of DNA methyltransferases 1, 3A, and 3B in sporadic breast carcinomas. Clin Cancer Res. 2003; 9:4415-4422.

19. Fang XY, Chen W, Fan JT, Song R, Wang L, Gu YH, Zeng GZ, Shen Y, Wu XF, Tan NH, Xu Q, Sun Y. Plant cyclopeptide RA-V kills human breast cancer cells by inducing mitochondria-mediated apoptosis through blocking PDK1-AKT interaction. Toxicol Appl Pharmacol. 2013; 267:95-103.

20. Lv H, Li Y, Du H, Fang J, Song X, Zhang J. The Synthetic Compound Norcantharidin Induced Apoptosis in Mantle Cell Lymphoma In Vivo and In Vitro through the PI3K-AktNF- kappa B Signaling Pathway. Evid Based Complement Alternat Med. 2013; 2013:461487.

21. Stein M, Bagnoli F, Halenbeck R, Rappuoli R, Fantl WJ, Covacci A. C-Src/Lyn kinases activate Helicobacter pylori CagA through tyrosine phosphorylation of the EPIYA motifs. Mol Microbiol. 2002; 43:971-980.
22. Hatakeyama M. Oncogenic mechanisms of the Helicobacter pylori CagA protein. Nature Reviews Cancer. 2004; 4:688-694.

23. Park SY, Yoo EJ, Cho NY, Kim N, Kang GH. Comparison of $\mathrm{CpG}$ islandhypermethylation and repetitive DNA hypomethylation in premalignant stages of gastric cancer, stratified for Helicobacter pylori infection. The Journal of pathology. 2009; 219:410-416.

24. Niwa T, Tsukamoto $T$, Toyoda $T$, Mori A, Tanaka H, Maekita $T$, Ichinose $M$, Tatematsu $M$, Ushijima $T$. Inflammatory processes triggered by Helicobacter pylori infection cause aberrant DNA methylation in gastric epithelial cells. Cancer Res. 2010; 70:1430-1440.

25. Ushijima T, Hattori N. Molecular Pathways: Involvement of Helicobacter pylori-Triggered Inflammation in the Formation of an Epigenetic Field Defect, and Its Usefulness as Cancer Risk and Exposure Markers. Clin Cancer Res. 2012; 18:923-929.

26. Burgers W, Blanchon L, Pradhan S, De Launoit Y, Kouzarides T, Fuks F. Viral oncoproteins target the DNA methyltransferases. Oncogene. 2007; 26:1650-1655.

27. Seo SY, Kim E-O, Jang KL. Epstein-Barr virus latent membrane protein 1 suppresses the growth-inhibitory effect of retinoic acid by inhibiting retinoic acid receptor- $\beta 2$ expression via DNA methylation. Cancer Lett. 2008; 270:66-76.

28. Tsai C-L, Li H-P, Lu Y-J, Hsueh C, Liang Y, Chen C-L, Tsao SW, Tse K-P, Yu J-S, Chang Y-S. Activation of DNA methyltransferase 1 by EBV LMP1 involves c-Jun NH2terminal kinase signaling. Cancer Res. 2006; 66:11668-11676.

29. Hino R, Uozaki H, Murakami N, Ushiku T, Shinozaki A, Ishikawa S, Morikawa T, Nakaya T, Sakatani T, Takada K. Activation of DNA methyltransferase 1 by EBV latent membrane protein 2A leads to promoter hypermethylation of PTEN gene in gastric carcinoma. Cancer Res. 2009; 69:2766-2774.

30. Maekita $T$, Nakazawa $K$, Mihara $M$, Nakajima $T$, Yanaoka K, Iguchi M, Arii K, Kaneda A, Tsukamoto T, Tatematsu M. High levels of aberrant DNA methylation in Helicobacter pylori-infected gastric mucosae and its possible association with gastric cancer risk. Clin Cancer Res. 2006; 12:989-995.

31. Li SP, Chen XJ, Sun AH, Zhao JF, Yan J. CagA(+) H. pylori induces Akt1 phosphorylation and inhibits transcription of p21(WAF1/CIP1) and p27(KIP1) via PI3K/Akt1 pathway. Biomed Environ Sci. 2010; 23:273-278.

32. Gastric J, Association C. Japanese classification of gastric carcinoma-2nd English edition. Gastric Cancer. 1998; 1:10-24.

33. Lauren $P$. The two histological main types of gastric carcinoma: diffuse and so-called intestinal-type carcinoma. an attempt at a histo-clinical classification. Acta Pathol Microbiol Scand. 1965; 64:31-49. 